\title{
Utilisation of ground granulated blast furnace slag (GGBFS) for soft soil improvement by deep mixing method
}

\author{
Nu Thi Nguyen*, Son Truong Bui, Hai Van Pham \\ Faculty of Geosciences and Geoengineering, Hanoi University of Mining and Geology, Vietnam
}

\begin{abstract}
ARTICLE INFO
ABSTRACT

Article history:

Received 19th Nov 2019

Revised 26 Jan. 2020

Accepted 28 ${ }^{\text {th }}$ Feb. 2020

Keywords:

GGBFS,

Unconfined compressive

strength,

Cement.

Ground granulated blast furnace slag (GGBFS) is the by-products from pig iron plants which can cause a serious problem for land, soil, and water. Thus, the study for reusing GGBFS is very nessesary. This paper presents the utilisation of GGBFS for soft soil improvement by cement deep mixing method. Portland cement was replaced by GGBFS from 0 to $100 \%$ and a total of 33 specimens were used to determine the unconfined compressive strength and deformation modulus of treated soil. The experimental results showed that replacement of GGBFS from 0 to $60 \%$ cement could increase the unconfined compressive strength and deformation modulus of treated soil. The optimum GGBFS content was found to be 30\% of cement content. In general, the utilisation of GGBFS for soil improvement could increase the properies of soft soil and soil treated with cement. The result of this study will be basic for utilisation of GGBFS in ground improvement by cement deep mixing method.
\end{abstract}

Copyright (C) 2020 Hanoi University of Mining and Geology. All rights reserved.

${ }^{*}$ Corresponding author

E-mail: nguyenthinu@humg.edu.vn

DOI: 10.46326/JMES.2020.61(1).10 


\title{
Tạp chí Khoa học Kỹ thuật Mỏ - Địa chất
}

\section{Nghiên cứu sử dụng xỉ lò cao nghiền mịn (GGBFS) trong cải tạo đất yếu bằng phương pháp cọc đất xi măng}

\author{
Nguyễn Thị Nụ * , Bùi Trường Sơn, Phạm Văn Hải \\ Khoa Khoa học và Kỹ thuật Địa chất, Trường Đại học Mỏ-Địa chất, Việt Nam
}

\begin{tabular}{|c|c|}
\hline THÔNG TIN BÀI BÁO & TÓM TẮT \\
\hline $\begin{array}{l}\text { Quá trình: } \\
\text { Nhận bài 19/11/2019 } \\
\text { Sửa xong 26/01/2020 } \\
\text { Chấp nhận đăng 28/02/2020 } \\
\text { Tù̀ khóa: } \\
\text { GGBFS, } \\
\text { Cường độ nở hông, } \\
\text { Xi măng. }\end{array}$ & 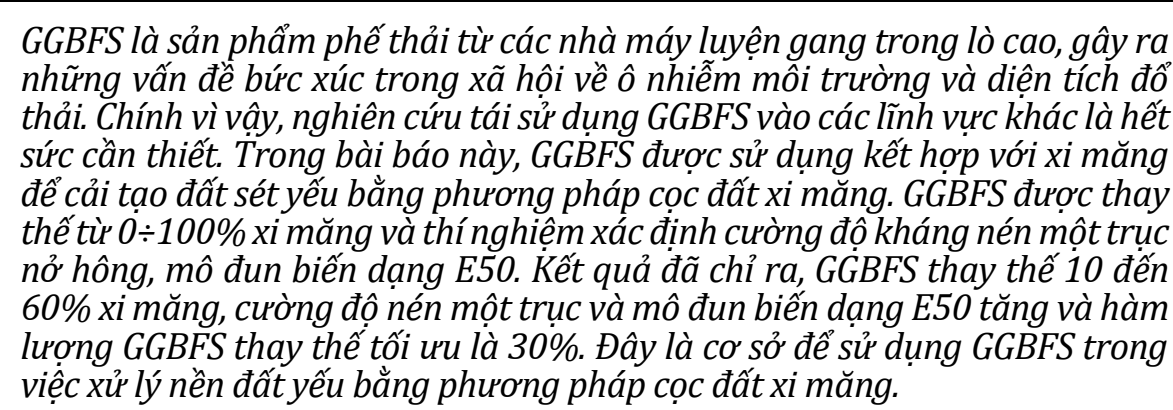 \\
\hline
\end{tabular}

(C) 2020 Trường Đại học Mỏ-Địa chất. Tất cả các quyền được bảo đảm.

\section{Mở đầu}

Xỉ hạt lò cao là sản phẩm phụ của nhà máy luyện gang trong lò cao. Công nghệ sản xuất gang và thép theo quy trình: quặng sắt, than cốc và vôi cục được đưa vào trong lò cao, nung và dưới quá trình hóa lý phức tạp tạo thành sản phẩm gang nóng chảy, đồng thời trải qua quá trình luyện thép để tạo nên các sản phẩm thép. Sản phẩm phụ của quá trình luyện gang thép là xỉ ở dạng nóng chảy, nhờ làm lạnh cực nhanh bằng nước áp lực cao sẽ tạo nên xỉ hạt lò cao. GGBFS là sản phẩm khi nghiền mịn xỉ hạt lò cao. Việc sử dụng GGBFS góp phần rất lớn trong việc giảm lượng xi măng qua đó sẽ giúp cho việc giảm lượng phát thải khí $\mathrm{CO}_{2}$ và gây ô nhiễm môi trường.

*Tác giả liên hệ

E-mail: nguyenthinu@humg.edu.vn DOI: 10.46326/JMES.2020.61(1).10
Theo thống kê hiện nay có 8 nhà máy luyện gang lò cao với tổng sản lượng gang là 7,27 triệu tấn/ năm, tương ứng với tổng lượng xỉ hạt lò cao phát sinh hàng năm tương ứng là 2,32 triệu tấn/ năm. Theo dự kiến, đến năm 2020, khi nhiều nhà máy luyện gang thép hoàn thành thì sẽ tạo ra lượng xỉ hạt lò cao hàng năm rất lớn, khoảng 4,8 triệu tấn xỉ hạt lò cao (Lê Việt Hùng và Vũ Văn Linh, 2019). Đây là con số không hề nhỏ thách thức với môi trường. Việc tích đọng các sản phẩm xỉ hạt lò cao chưa được tiêu thụ gây ô nhiễm môi trường đất, nước và không khí, mất diện tích lớn đổ thải.

Trên thế giới, GGBFS được sử dụng trong nhiều lĩnh vực. Trong lĩnh vực cải tạo đất, GGBFS được sử dụng kết hợp với các chất kết dính vô cơ. GGBFS được sử dụng để cải tạo đất lateritic (Akimusuri, 1991) nhằm tăng cường độ và khả năng đầm chặt của đất. Kết quả nghiên cứu này cũng chỉ ra hàm lượng GGBFS tối ưu để cải tạo đất 
laterit. GGBFS kết hợp với vôi để cải tạo đất làm cường độ, giá trị CBR của đất cải tạo được cải thiện (Gupta và nnk., 1989; Padmaraj và nnk., 2017; Mohil và nnk., 2019; Darwish và nnk., 2019). Các kết quả nghiên cứu cũng đều chỉ ra hàm lượng tối ưu của GGBFS và vôi để cải tạo đất. GGBFS cũng được kết hợp sử dụng với chất kết dính vô cơ (xi măng, vôi) làm giảm tính chất trương nở của đất và cải thiện các tính chất của đất trương nở (Sekhar và nnk., 2017; Sharma và nnk., 2015; Higgins và nnk., 1998; Celik và nnk., 2013).

Tại Việt Nam, việc tái sử dụng các loại xỉ gang và xỉ thép đã được chính phủ thúc đẩy và nhằm thay thế các nguồn vật liệu tự nhiên (TCVN 11568: 2016; Bộ xây dựng, 2017). GGBFS đã được dùng là phụ gia hoạt tính cho sản xuất xi măng, bê tông và vữa (Nguyễn Văn Chánh và Trần Vũ Minh Nhật, 2014; Tăng Văn Lâm, 2010, Lê Việt Hùng và nnk., 2016). Xỉ thép được sử dụng làm nền đường giao thông và xử lý nền đất yếu (Nguyễn Trường Tiến, 2013).

Như vậy, có thể thấy trên thế giới và Việt Nam, GGBFS đã được sử dụng trong nhiều lĩnh vực, tuy nhiên tính chất kỹ thuật của GGBFS rất khác nhau tùy thuộc vào công nghệ luyện gang. Mặt khác, việc ứng dụng GGBFS vào trong việc xử lý nền đất yếu bằng cọc đất xi măng hầu như chưa được nghiên cứu. Hơn nữa, cọc đất xi măng là một trong những giải pháp xử lý nền đất yếu đang được ứng dụng rộng rãi tại Việt Nam, nên khả năng sử dụng GGBFS là rất lớn. Do vậy, bài báo trình bày các kết quả nghiên cứu về việc sử dụng GGBFS trong việc cải tạo đất yếu bằng phương pháp cọc đất xi măng thông qua thí nghiệm trong phòng. Từ kết quả nghiên cứu có thể đánh giá nhận định về triển vọng thay thế xi măng của GGBFS trong lĩnh vực xử lý nền đất yếu.

\section{Vật liệu và phương pháp nghiên cứu}

\subsection{Vật liệu sử dụng}

Đất yếu được lấy tại vùng ven biển thuộc Sầm Sơn, tỉnh Thanh Hóa. Độ sâu phân bố từ mặt đất đến khoảng $10 \mathrm{~m}$. Đất yếu được lấy mẫu nguyên trạng để xác định thành phần hạt, các chỉ tiêu vật lý và cơ học của đất (Bảng 1 ). Qua kết quả nghiên cứu cho thấy, đất yếu thuộc dạng bùn sét, màu xám, xám đen.

GGBFS được sản xuất bởi tập đoàn Hòa Phát với độ mịn tương ứng là S95. Xi măng sử dụng là xi măng PC 40 Bút Sơn. Thành phần hóa học của xi măng Bút Sơn và GGBFS như Bảng 2.

\subsection{Phương pháp nghiên cúru}

Đất yếu được lấy từ hố khoan và lấy 100\% lõi khoan, bảo quản ở trạng thái tự nhiên, vận chuyển về phòng thí nghiệm. Đất yếu được trộn xi măng và GGBFS với các hàm lượng khác nhau.

Bảng 1. Thành phần hạt và các chỉ tiêu co lý của đất yếu.

\begin{tabular}{|c|c|c|c|c|}
\hline TT & \multicolumn{2}{|r|}{ Các chỉ tiêu cơ lý } & Đơn vị & Giá trị trung bình \\
\hline \multirow{3}{*}{1} & \multirow{3}{*}{$\begin{array}{l}\text { Thành phần } \\
\text { hạt, \% }\end{array}$} & Nhóm hạt cát $(>0,05 \mathrm{~mm})$ & \multirow{3}{*}{$\%$} & 23,5 \\
\hline & & Nhóm hạt bụi $(0,05-0,005 \mathrm{~mm})$ & & 36,7 \\
\hline & & Nhóm hạt sét, $<0,005 \mathrm{~mm}$ & & 39,8 \\
\hline 2 & \multicolumn{2}{|c|}{ Độ ẩm tự nhiên, $w$} & $\%$ & 91,2 \\
\hline 4 & \multicolumn{2}{|c|}{ Khối lượng thể tích tự nhiên, $g$} & $\mathrm{~T} / \mathrm{m}^{3}$ & 1,379 \\
\hline 5 & \multicolumn{2}{|c|}{ Khối lượng thể tích khô, $g_{c}$} & $\mathrm{~T} / \mathrm{m}^{3}$ & 0,72 \\
\hline 6 & \multicolumn{2}{|c|}{ Khối lượng riêng, $D$} & $\mathrm{~T} / \mathrm{m}^{3}$ & 2,62 \\
\hline 7 & \multicolumn{2}{|c|}{ Hệ số rỗng, $e$} & - & 2,633 \\
\hline 8 & \multicolumn{2}{|l|}{ Độ lỗ rỗng, $n$} & $\%$ & 72,5 \\
\hline 9 & \multicolumn{2}{|c|}{ Giới hạn chảy, $L L$} & $\%$ & 82,5 \\
\hline 10 & \multicolumn{2}{|c|}{ Giới hạn dẻo, $P P$} & $\%$ & 43,6 \\
\hline 11 & \multicolumn{2}{|l|}{ Chỉ số dẻo, $I_{P}$} & $\%$ & 38,9 \\
\hline 12 & \multicolumn{2}{|l|}{ Độ sệt, $I_{S}$} & - & 1,22 \\
\hline 13 & \multicolumn{2}{|l|}{$\mathrm{pH}$ value } & - & 7,3 \\
\hline 14 & \multicolumn{2}{|c|}{ Cường độ kháng nén nở hông, $q_{u}$} & $\mathrm{kG} / \mathrm{cm}^{2}$ & 0,053 \\
\hline 15 & \multicolumn{2}{|c|}{ Hệ số nén lún, $a_{1-2}$} & $\mathrm{~cm}^{2} / \mathrm{kG}$ & 0,123 \\
\hline
\end{tabular}


Bảng 2. Thành phần hóa học của xi măng PC40 và GGBFS.

\begin{tabular}{|c|c|c|c|}
\hline \multirow{2}{*}{ TT } & \multirow{2}{*}{ Oxit } & \multicolumn{2}{|c|}{ Hàm lượng \% } \\
\cline { 3 - 4 } & & GGBFS & Xi măng PC 40 Bút Sơn \\
\hline 1 & $\mathrm{SiO}_{2}$ & 36,88 & 19,74 \\
\hline 2 & $\mathrm{Al}_{2} \mathrm{O}_{3}$ & 12,29 & 5,18 \\
\hline 3 & $\mathrm{Fe}_{2} \mathrm{O}_{3}$ & 0,15 & 3,11 \\
\hline 4 & $\mathrm{CaO}$ & 38,45 & 63,14 \\
\hline 5 & $\mathrm{MgO}$ & 7,52 & 1,61 \\
\hline 6 & $\mathrm{Na}_{2} \mathrm{O}$ & 0,21 & 0,15 \\
\hline 7 & $\mathrm{~K}_{2} \mathrm{O}$ & 0,76 & 0,70 \\
\hline 8 & $\mathrm{SO}_{3}$ & 0,04 & 1,85 \\
\hline 9 & $\mathrm{TiO}_{2}$ & 0,75 & 0,12 \\
\hline 10 & $\mathrm{FeO}_{2}$ & 0,31 & - \\
\hline 11 & $\mathrm{MnO}$ & 1,23 & - \\
\hline 12 & $\mathrm{LOI}$ & - & 2,58 \\
\hline \multicolumn{4}{|c|}{ LOI-Hàm lượng mất khi nung. } \\
\hline
\end{tabular}

Lựa chọn hàm lượng xỉ măng là $150 \mathrm{~kg} / \mathrm{m}^{3}$ và thay thế xi măng bằng $0,10,20,30,40,50,60,70$, 80, 90, 100\% GGBFS.

Mẫu đất được xác định độ ẩm và khối lượng thể tích tự nhiên, kết quả thành phần hạt và chỉ tiêu cơ lý được trình bày ở Bảng 1 .

Đất được trộn đều ở độ ẩm tự nhiên và chia thành nhiều phần để trộn với các hàm lượng xi măng + GGBFS khác nhau. Theo thực tế sản xuất, hầu hết các dự án đều sử dụng phương pháp trộn ướt với tỷ lệ nước/ xi măng là $1 / 1,25$. Do vậy, trong nghiên cứu này nhóm tác giả đã tiến hành sử dụng phương pháp thi công cọc đất xi măng theo phương pháp trộn ướt với tỷ lệ nước/ xi măng là $1 / 1,25$.
Ở mỗi phần đất, hỗn hợp được trộn đều trong máy trộn trong vòng 5 phút và cho vào khuôn hình trục tròn có chiều cao bằng $10 \mathrm{~cm}$ và đường kính là $5 \mathrm{~cm}$. Mẫu được gia công theo phương pháp đầm rung, đảm bảo không bị rỗng giữa, không có túi khi trong mẫu sau khi đúc.

Mẫu sau khi đúc xong, để nguyên trong khuôn và cho vào tủ dưỡng hộ (nhiệt độ $27^{\circ} \mathrm{C}$, độ ẩm $95 \%$ ) trong vòng 3 ngày, lấy và tháo khuôn, đưa vào ngâm trong bể nước với tổng thời gian bảo dưỡng là 28 ngày. Mẫu được gia công và bảo dưỡng theo tiêu chuẩn Việt Nam TCVN 9403:2012.

Mỗi tổ hợp mẫu ở mỗi hàm lượng xi măng và GGBFS là 3 mẫu, tổng số lượng mẫu nghiên cứu ở 28 ngày tuổi là 33 mẫu (Bảng 3). Đến 28 ngày tuổi, mẫu được vớt ra và để ráo nước, xác định khối lượng thể tích và thí nghiệm nén một trục nở hông để xác định cường độ kháng nén nở hông $\left(q_{u}\right)$ và mô đun biến dạng $E_{50}$. Thí nghiệm nén nở hông với tốc độ $1 \mathrm{~mm} /$ phút đến khi mẫu phá hủy theo tiêu chuẩn ASTM D2166. Lập mối quan hệ giữa ứng suất và biến dạng của mẫu. Từ đó, xác định mô đun biến dạng $E_{50}$ và cường độ kháng nén nở hông $q_{u}$ của hỗn hợp gia cố.

\section{Kết quả nghiên cứu và thảo luận}

\subsection{Cường độ kháng nén nở hông của hỗn hợp đất gia cố}

Kết quả xác định cường độ kháng nén nở hông của các hỗn hợp đất gia cố được trình bày ở các Hình 1, 2.

Bảng 3. Bảng tổng hợp số lượng mẫu gia cố cọc đất xi măng + GGBFS.

\begin{tabular}{|c|c|c|c|c|c|}
\hline TT & $\begin{array}{l}\text { Kí hiệu } \\
\text { tổ mẫu }\end{array}$ & $\begin{array}{l}\text { Tỷ lệ gia cố xi măng }(\mathrm{X})+ \\
\text { GGBFS }\end{array}$ & Hàm lượng chất kết dính $\left(\mathrm{kg} / \mathrm{m}^{3}\right)$ & $\begin{array}{l}\text { Tỷ lệ nước/ } \\
\text { xi măng }\end{array}$ & $\begin{array}{c}\text { Số lượng } \\
\text { mẫu }\end{array}$ \\
\hline 1 & M0 & $100 \% \mathrm{X}$ & $150 \mathrm{~kg} \mathrm{XM}$ & $1 / 1,25$ & 3 \\
\hline 2 & M1 & $90 \% \mathrm{X}+10 \% \mathrm{GGBFS}$ & 135 kg XM+15kg GGBFS & $1 / 1,25$ & 3 \\
\hline 3 & M2 & $80 \% \mathrm{X}+20 \%$ GGBFS & $120 \mathrm{~kg} X \mathrm{X}+30 \mathrm{~kg}$ GGBFS & $1 / 1,25$ & 3 \\
\hline 4 & M3 & $70 \% \mathrm{X}+30 \%$ GGBFS & $105 \mathrm{~kg}$ XM+45kg GGBFS & $1 / 1,25$ & 3 \\
\hline 5 & M4 & $60 \% \mathrm{X}+40 \%$ GGBFS & $90 \mathrm{~kg}$ XM+60kg GGBFS & $1 / 1,25$ & 3 \\
\hline 6 & M5 & $50 \% \mathrm{X}+50 \%$ GGBFS & $75 \mathrm{~kg}$ XM+75kg GGBFS & $1 / 1,25$ & 3 \\
\hline 7 & M6 & $40 \% \mathrm{X}+60 \% \mathrm{GGBFS}$ & $60 \mathrm{~kg} X \mathrm{XM}+90 \mathrm{~kg}$ GGBFS & $1 / 1,25$ & 3 \\
\hline 8 & M7 & $30 \% \mathrm{X}+70 \% \mathrm{GGBFS}$ & $45 \mathrm{~kg}$ XM+105kg GGBFS & $1 / 1,25$ & 3 \\
\hline 9 & M8 & $20 \% \mathrm{X}+80 \%$ GGBFS & $30 \mathrm{~kg} X M+120 \mathrm{~kg}$ GGBFS & $1 / 1,25$ & 3 \\
\hline 10 & M9 & $10 \% \mathrm{X}+90 \%$ GGBFS & $15 \mathrm{~kg}$ XM+135kg GGBFS & $1 / 1,25$ & 3 \\
\hline 11 & M10 & $100 \%$ GGBFS & $0 \mathrm{~kg} X \mathrm{XM}+150 \mathrm{~kg}$ GGBFS & $1 / 1,25$ & 3 \\
\hline
\end{tabular}




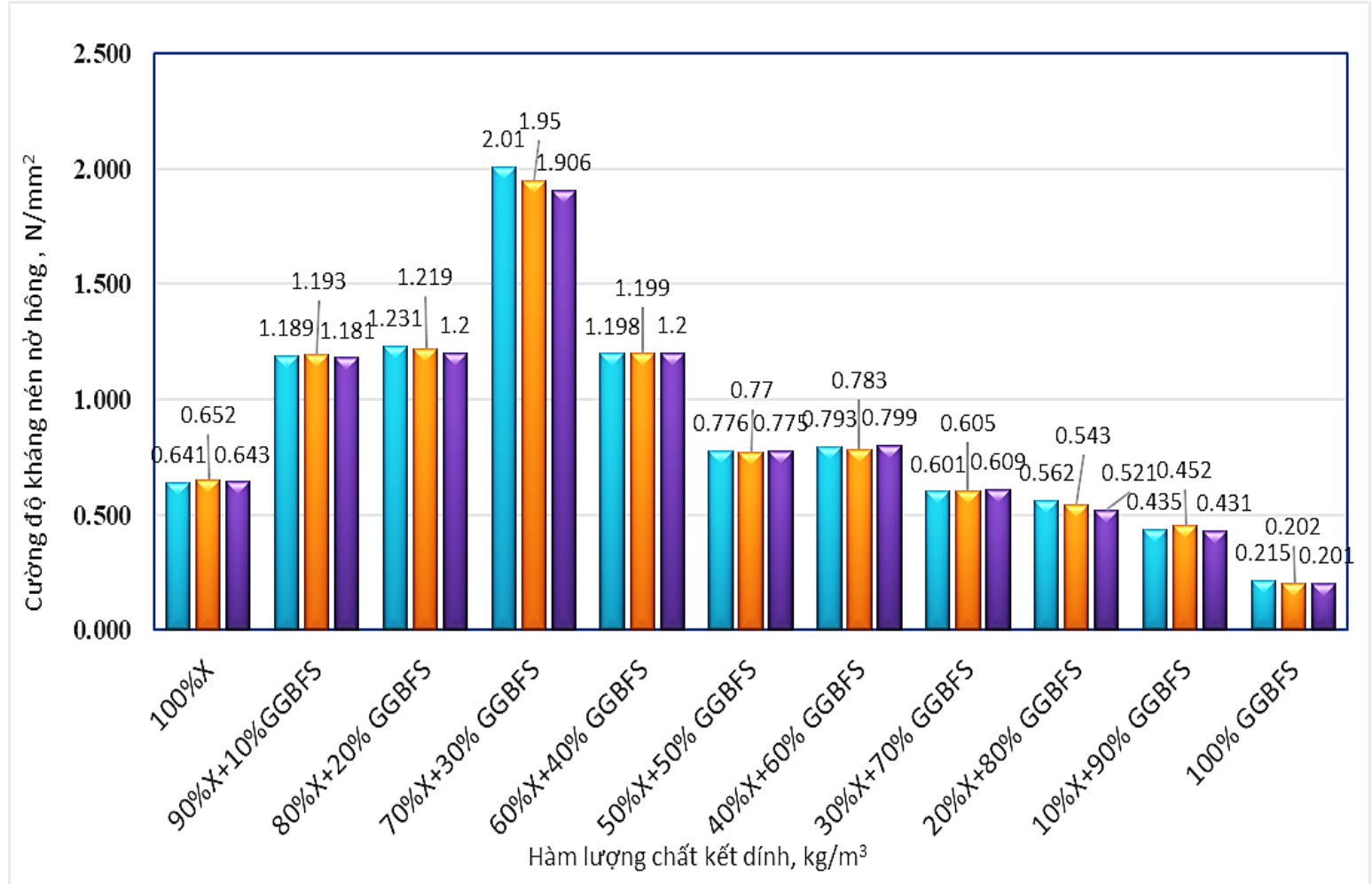

Hình 1. Cường độ kháng nén nở hông của tổ hợp mẫu đất gia cố đất xi măng+ GGBFS với các tỷ lệ khác nhau.

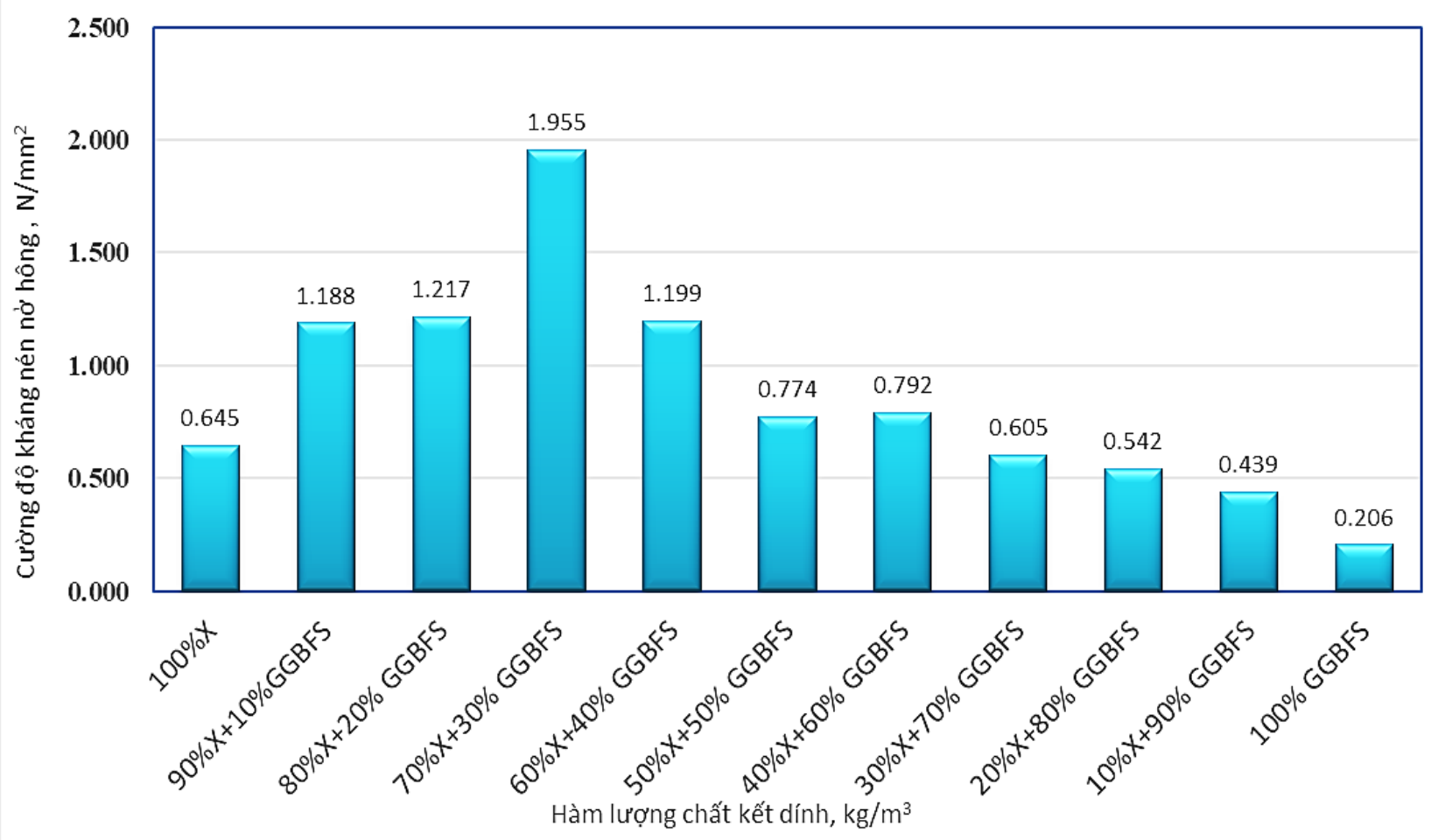

Hình 2. Cường độ kháng nén nở hông trung bình của tổ hợp mẫu đất gia cố đất xi măng+ GGBFS với các tỷ lẹ khác nhau. 
Từ kết quả ở Hình 1,2 cho thấy, GGBFS thay thế $10 \div 60 \%$ xi măng, cường độ kháng nén nở hông tăng từ 19 đến $200 \%$ (tổ hợp mẫu M1 - M6) so với đất gia cố $100 \%$ xi măng (tổ hợp mẫu M0). Cường độ của hỗn hợp gia cố lớn nhất tương ứng với tổ hợp mẫu M3 (70\% xi măng +30\% GGBFS). Điều này có thể giải thích là khi gia cố đất bằng xi măng và GGBFS, xảy ra các phản ứng hóa lý giữa đất, xi măng và GGBFS, tạo nên các sản phẩm gắn kết các hạt đất lại với nhau, từ đó cường độ hỗn hợp tăng.

Thành phần khoáng vật chính của xi măng pooc lăng là $\mathrm{C}_{3} \mathrm{~S}, \mathrm{C}_{2} \mathrm{~S}, \mathrm{C}_{3} \mathrm{~A}$ tác dụng với nước trong lỗ rỗng của đất tạo nên các sản phẩm thủy hóa $\mathrm{C}$ $\mathrm{S}-\mathrm{H}, \mathrm{Ca}(\mathrm{OH})_{2}$ hoặc $\mathrm{C}_{3} \mathrm{AH}_{6}$. Sau đó, $\mathrm{Ca}(\mathrm{OH})_{2}$ sẽ tác dụng với cấu tử của GGBFS để tạo thêm pha rắn có tính kết dính.

$3 \mathrm{Ca}(\mathrm{OH})_{2}+2 \mathrm{~S}_{\mathrm{i}} \mathrm{O}_{2}$ vô định hình $+\mathrm{H}_{2} \mathrm{O} \rightarrow 3 \mathrm{CaO}$. $2 \mathrm{SiO}_{2} \cdot \mathrm{H}_{2} \mathrm{O}$

$3 \mathrm{Ca}(\mathrm{OH})_{2}+2 \mathrm{Al}_{2} \mathrm{O}_{3}$ hoạt tính $+6 \mathrm{H}_{2} \mathrm{O} \rightarrow 3 \mathrm{CaO}$. $\mathrm{Al}_{2} \mathrm{O}_{3} \cdot \mathrm{H}_{2} \mathrm{O}$

$3 \mathrm{Ca}(\mathrm{OH})_{2}+2 \mathrm{~S}_{\mathrm{i}} \mathrm{O}_{2}$ vô định hình $+\mathrm{H}_{2} \mathrm{O} \rightarrow 3 \mathrm{CaO}$. $2 \mathrm{SiO}_{2} \cdot \mathrm{H}_{2} \mathrm{O}$

Các sản phẩm này làm tăng tỷ lệ rắn/ lỏng trong hệ và tăng cường độ của hỗn hợp đất gia cố xi măng +GGBFS so với gia cố bằng xi măng (Phạm Mạnh Huy, 2016).

Tuy nhiên, GGBFS thay thế $70 \div 100 \%$ xi măng (các tổ hợp mẫu $\mathrm{M} 7 \div \mathrm{M} 10$ ) thì cường độ giảm 6 đến 68\% so với tổ hợp mẫu M0 (100\% xi măng). Điều này cho thấy, chỉ khi sử dụng hỗn hợp xi măng +GGBFS trong giới hạn thích hợp sẽ làm tăng cường độ của hỗn hợp đất gia cố do mật độ sản phẩm thủy hóa tăng, cải thiện vùng tiếp giáp giữa đá xi măng và hạt đất, từ đó tăng cường độ của đất gia cố (Lê Việt Hùng và Vũ Văn Linh, 2019). Khi vượt quá giới hạn này, gia cố bằng xi măng +GGBFS cũng có tác dụng cải tạo đất nhưng không hiệu quả so với cải tạo đất bằng xi măng. Mohil và nnk., (2019) đã tiến hành xác định cường độ kháng nén nở hông của hỗn hợp đất yếu với GGBFS tại độ ẩm tối ưu và khối lượng thể tích khô lớn nhất cho kết quả hàm lượng GGBFS tối ưu để cải tạo đất sét yếu là $6 \%$. Khi hàm lượng GGBFS sử dụng đến $12 \%$ thì cường độ nở hông của đất gia cố giảm. (Sharma và nnk., 2016) cũng chỉ ra hàm lượng tối ưu để cải tạo đất trương nở để cường độ của đất đạt lớn nhất là $20 \%$ (tro bay + GGBFS)+1\% vôi. (Padmaraj và nnk., 2017) đưa ra hàm lượng GGBFS tối ưu để đạt được cường độ lớn nhất là $10 \%$ khi cải tạo đất yếu.

\subsection{Mô đun biến dạng E50 của hỗn hợp đất gia cố}

Mô đun biến dạng $E_{50}$ được xác định từ đồ thị đường cong mối quan hệ giữa ứng suất và biến dạng trong thí nghiệm nén một trục nở hông. Giá trị $E_{50}$ được xác định bằng hệ số góc của đường thẳng tính từ gốc tọa độ đến $q_{u} / 2$. Kết quả nghiên cứu xác định mô đun biến dạng $E_{50}$ của hỗn hợp gia cố được trình bày ở Hình 3,4 .

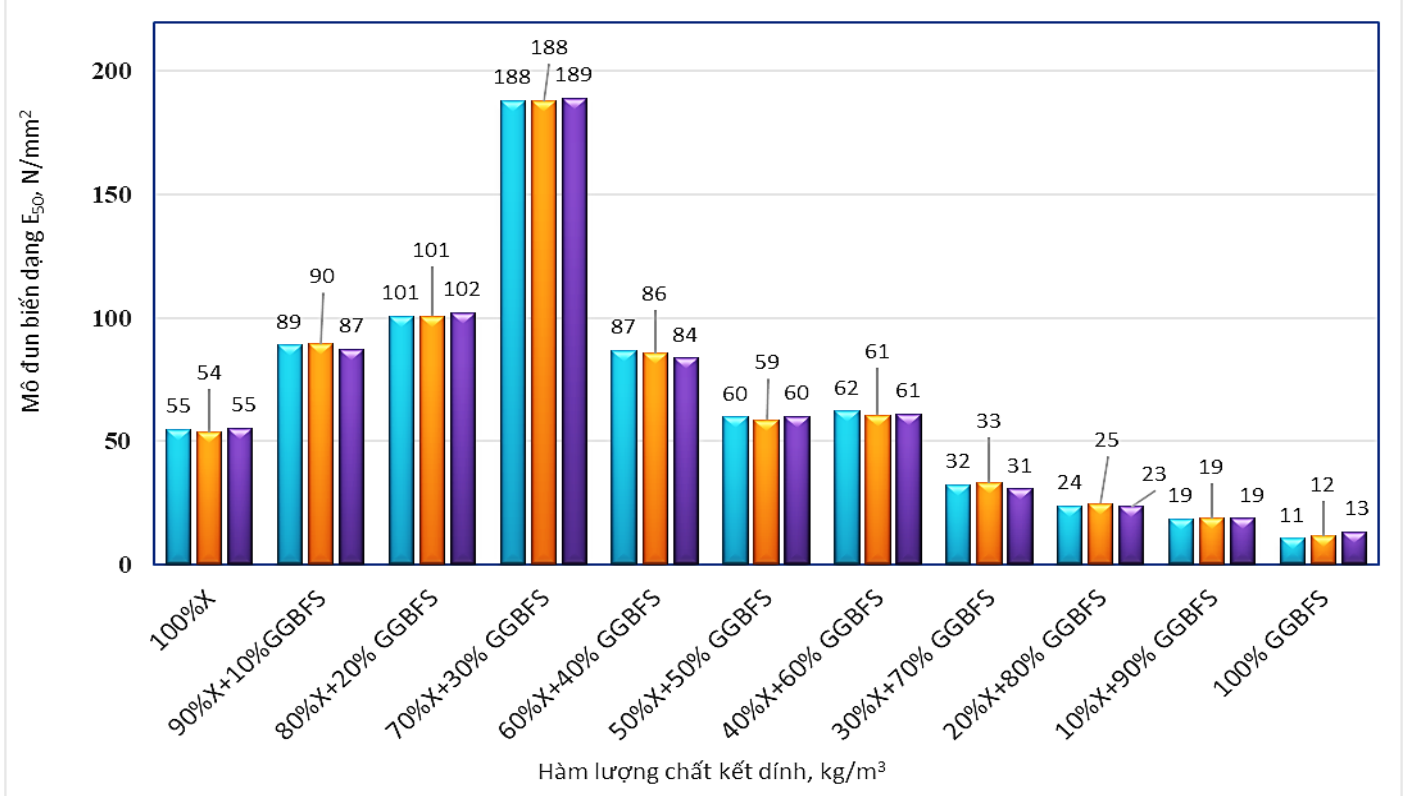

Hình 3. Mô đun biến dạng $E_{50}$ của tổ hợp mẫu đất gia cố đất xi măng +GGBFS với các tỷ lệ khác nhau. 
Kết quả chỉ ra, cũng giống như cường độ kháng nén nở hông, mô đun biến dạng $E_{50}$ tăng từ $9 \div 245 \%$ khi thay thế GGBFS bằng $10 \div 60 \%$ xi măng (các tổ hợp mẫu từ M1 đến M6). Mô đun của hỗn hợp giảm khi GGBFS thay thế xi măng đến $70 \%$, và nhỏ nhất khi hàm lượng xỉ thay thế $100 \%$ xi măng, giảm $41 \div 78 \%$.
3.3. Mối quan hệ giũ̃a cường độ kháng nén nở hông và mô đun biến dạng $E_{50}$ của hỗn hợp gia cố

Mối quan hệ giữa mô đun biến dạng và cường độ kháng nén nở hông được trình bày ở Hình 5 và công thức (1).

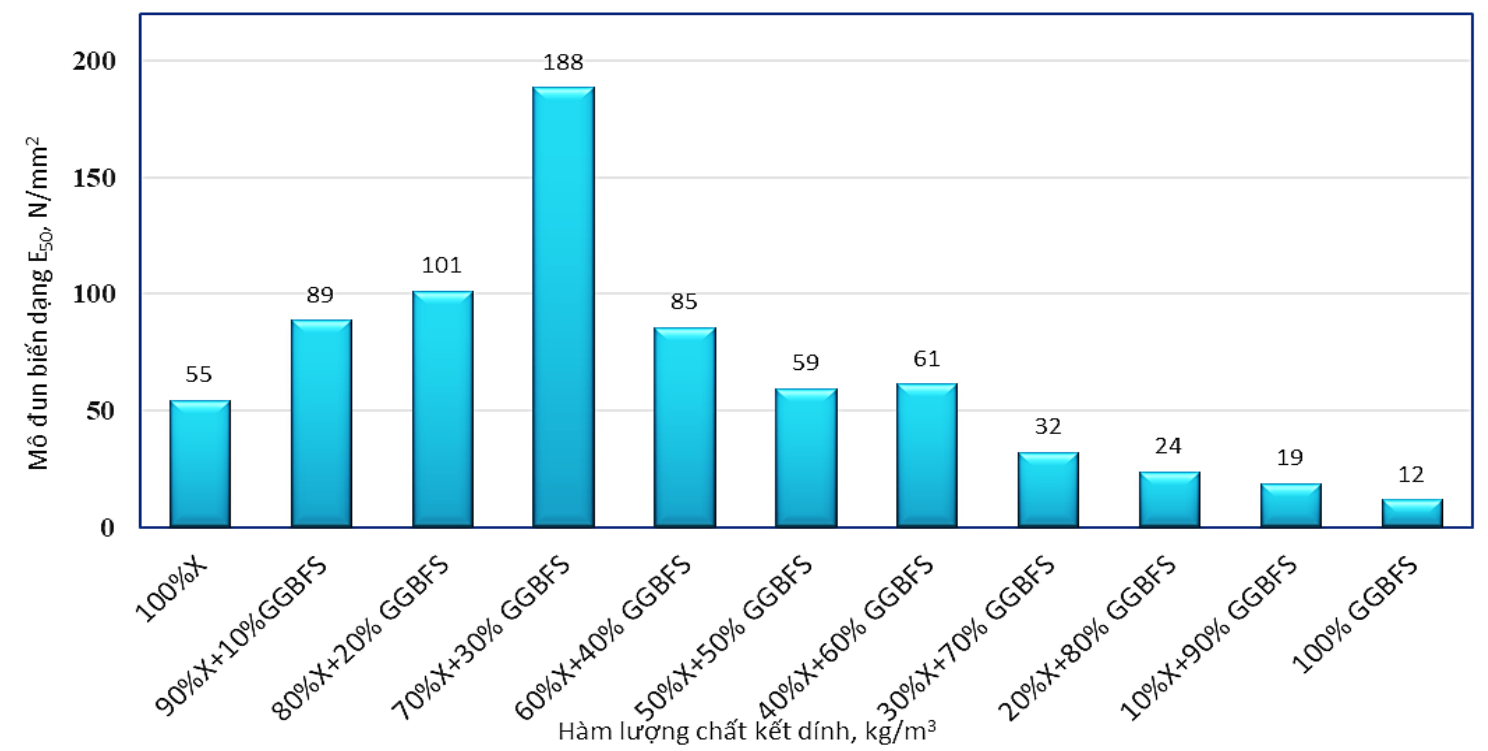

Hình 4. Mô đun biến dạng $E_{50}$ trung bình của tổ hợp mẫu đất gia cố đất xi măng +GGBFS với các tỷ lệ khác nhau.

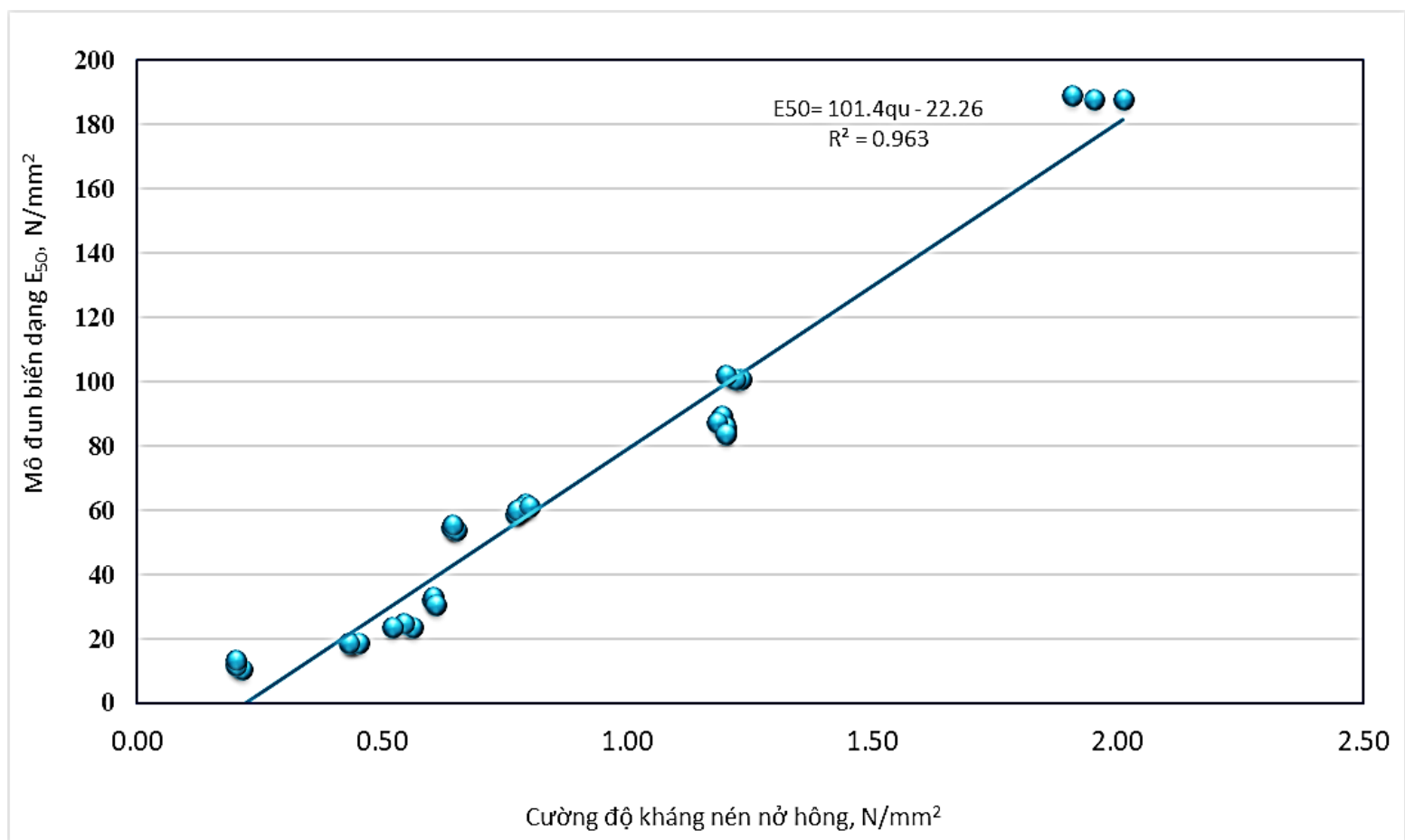

Hình 5. Mối quan hệ giữa mô đun biến dạng và cường độ kháng nén nở hông của hỗn hợp đất gia cốxi măng +GGBFS. 


$$
E_{50}=101,4 q_{u}-22,26
$$

Trong đó: Hệ số tương quan $R^{2}=0,963$; Mô đun biến dạng $E_{50}$ bằng 44,1 $\div 99,2$ lần cường độ kháng nén nở hông $q_{u}$.

Mối quan hệ giữa $E_{50}$ và $q_{u}$ tùy thuộc vào loại đất và tỷ lệ nước/ xi măng khác nhau. Fang và nnk., (2001) thiết lập mối quan hệ với phương trình $E_{50}=30-300 q_{u}$ cho đất gia cố bằng xi măng truyền thống PC. Vũ Ngọc Bình (2018) chỉ ra mỗi quan hệ giữa mô đun biến dạng và chất kết dính vô cơ cải tạo đất vùng đồng bằng sông Cửu Long là $50 q_{u}<E_{50}<184 q_{u}$.

\section{Kết luận}

Qua kết quả nghiên cứu, rút ra một số nhận xét sau:

- Hỗn hợp gia cố đất yếu + xi măng và GGBFS với hàm lượng GGBFS thay thế từ $10 \div 60 \%$ có cường độ và mô đun biến dạng lớn hơn so với hỗn hợp gia cố đất yếu + xi măng.

- Hàm lượng tối ưu trong cải tạo đất bùn sét yếu là 30\% GGBFS thay thế xi măng PC40. Kết quả cho thấy, cường độ và mô đun biến dạng lớn hơn nhiều so với hỗn hợp gia cố khác.

- Khi sử dụng GGBFS trong xử lý nền đất yếu bằng xi măng kiến nghị sử dụng trong khoảng từ $30 \div 60 \%$ mà vẫn đảm bảo được yêu cầu kỹ thuật giống như xi măng pooc lăng truyền thống.

\section{Tài liệu tham khảo}

Akimisuru, J. Q., (1991). Potential beneficial uses of steel slag wastes for Civil engineering purposes. Resources Conservation and Recycling 5(1), 73-80.

Bộ Xây dựng (2017). Quyết định số 430/QĐ - BXD năm 2017 v/v ban hành "Chỉ dẫn kỹ thuật sử dụng xỉ gang, xỉ thép làm vật liệu xây dựng".

Celik, E., Nalbantoglu, Z., (2013). Effects of ground blastfurnace slag (GGBS) on the swelling properties of lime-stabilzaed sulfate-bearing soils. Engineering geology 163, 20-25.

Darwish, G. S., Tangri, A.P., Hajizada, B. (2019). Effects of Ground Granulated Blast Furnace Slag \& Lime on the Engineering Properties of Clayey Soil: A Review. International Journal of Technical Innovation In Modern Engineering \& Science 5(5).
Fang, Y. S.,Chungy, Y. T., Yu, F. J., and Chen, T. J., (2001). Properties of soil - cement stabilised with deep mixing method, Ground Improvement 5(2), 69-74.

Gupta, S. , and Seehra, S. S., (1989). Studies on Lime -Granulated Blast Furnace Slag as an Alternative Binder to Cement. Highways Research Board. Bulletin 38, 81-97.

Higgins, D. D., Kinuthia, J. M., and Wild. S. (1998). Soil stabilization using lime-actived GGBS. Proceddings of the 6' Int. Conference, Fly ash, Silica fume, Slag, and Natural Pozzolans in Concrete 2, 1057-1074. Bangkok, Thai Land.

Lê Việt Hùng, (2016). Hiện trạng các quy định và tiêu chuẩn về sử dụng xỉ gang, xỉ thép ở Việt Nam. Hội thảo úng dụng xỉ gang và xỉ thép trong ngành xây dựng vì sự phát triển bền vũng. Hà Nội tháng 12/2016.

Lê Việt Hùng, Vũ Văn Linh (2019). Tính chất của bê tông sử dụng xỉ hạt lò cao nghiền mịn làm phụ gia khoáng. Tạp chí Nghiên cứu và phát triển Vật liệu xây dựng 1, 29-39.

Mohil, P., Siddaharth, P., Twinkal, P., Smit, P., Rana, K., (2019). Stabilisation of Soft Soil using Ground Granulated Blastfurnace Slag and Lime. International Research Journal of Engineering and Technology 6(4), 3557-3562.

Nguyễn Trường Tiến (2013). Nghiên cứu sử dụng xỉ thép làm nền đường giao thông và xử lý sâu nền đất yếu vì sự phát triển xanh. Báo cáo tổng kết đề tài.

Nguyễn Văn Chánh, Trần Vũ Minh Nhật, (2014). Nghiên cứu dùng xỉ trong công nghệp sản xuất xi măng Portland xỉ. Luận văn Thạc sỹ.

Padmaraj, D., \& Chandrakaran S., (2017). Stabilisation of soft clay using ground granulated blastfurnace slag and lime. Sixth Indian Young Geotechnical Engineers Conference 6IYGEC2017.

Phạm Mạnh Huy (2016). Xỉ lò cao trong sản xuất xi măng và bê tông, Thông tin khoa học - Công nghệ 1/2016, 23-28.

Sekhar, C. D, Sitaram Nayak, H. K. Preetha, (2017). Influence of Granulated Blast Furnace Slag and Cement on the Strength Properties of Lithomargic Clay. Indian Geotech J. 
Sharma, A. K., Sivipullaiah, P. V. (2015). Ground granulated blast furnace slag amended fly ash as an expansive soil stabilizer. Soils and foundation, 56 (2), 205-212.

Tăng Văn Lâm (2010). Nghiên cứu sử dụng phế thải xỉ luyện kim của nhà máy Gang thép-Thái Nguyên dùng làm phụ gia chế tạo bê tông trong các công trình xây dựng tại tỉnh Thái Nguyên. Đề tài cấp trường. Mã số T2010 - 04. Đại học kỹ thuật Công nghiệp Thái Nguyên.
TCVN 11568:2016, (2016). Xỉ lò cao nghiền mịn cho bê tông và vữa xây dựng.

TCVN 9403:2012, (2012). Gia cố nền đất yếuPhương pháp trụ đất xi măng

Vũ Ngọc Bình (2018). Nghiên cứu ảnh hưởng đặc tính xây dựng của đất loại sét yếu vùng đồng bằng sông Cửu Long đến chất lượng gia cố nền bằng xi măng kết hợp với phụ gia trong xây dựng công trình. Luận án tiến sĩ kỹ thuật. Hà Nội. 